\title{
Boneca Gertrudes: identidade feminina e práticas educativas em Saúde*
}

\author{
Cláudia Maria Bógus ${ }^{1}$ \\ Áurea Maria Zöllner Ianni²
}

BÓGUS, C. M., IANNI, A. M. Z. The Gertrudes Doll: female identity and educational practices in health care. Interface - Comunicação, Saúde, Educação, v.3, n.4, 1999.

The 1984 introduction of the Women's Health Integral Assistance Program, incorporating the female identity issue (i.e., seeking to view women relative to their body and sexuality, as well as the way in which these representations related to the social significance of motherhood), resulted in its becoming essential to rethink the health services practices carried out up to then. With a view to aiding the educational activities of health professionals, a pedagogical tool was devised at the time: the Gertrudes Doll. The present research project, conducted during 1995 and 1996, assessed the reach of this pedagogical tool, taking into account its diversity of uses in educational practices in the health care field and, mainly, whether this variety of uses was the result of the pedagogical properties that constitute the Gertrudes Doll: the expression of a dialogical methodology and the concretization of the female body. This investigation intends to contribute to the discussion on the development of further tools, dealing with gender issues, for assisting educational work in the health care field.

KEY WORDS: health education, gender and sexuality, women's health.

A implantação, em 1984, do Programa de Assistência Integral à Saúde da Mulher, ao incorporar a questão da identidade feminina - procurando ver a mulher em relação ao seu corpo e à sua sexualidade e de que forma estas representações se relacionavam com o significado social da maternidade - tornou fundamental repensar a prática dos serviços de saúde realizada até então. Com o objetivo de auxiliar a atuação educativa dos profissionais de saúde, foi elaborado, na época, um instrumento pedagógico: a Boneca Gertrudes. Esta pesquisa, realizada nos anos de 1995 e 1996, verificou a abrangência deste instrumento pedagógico, considerando sua diversidade de usos nas práticas educativas em saúde e, principalmente, se esta abrangência de usos deve-se ao recurso pedagógico constituinte da Boneca Gertrudes: expressão da metodologia dialógica e concretização do corpo feminino. A investigação pretende contribuir para a discussão da elaboração de novos recursos facilitadores para o trabalho educativo em saúde, que abordem questões de gênero.

PALAVRAS-CHAVE: educação em Saúde, gênero e sexualidade, saúde da mulher.

\footnotetext{
* Projeto desenvolvido pelo Núcleo de Investigação em Educação e Saúde do Instituto de Saúde SES/SP, coordenado pelas autoras do trabalho e equipe técnica formada por Monica Thais Simões Matsukura; Denise Nudel; Claudete Gomes dos Santos; Risodalva Gonçalves; Marli Fernandes Carneiro e Eduardo Peduto (Aprimorando/Fundação do Desenvolvimento Administrativo - Fundap).

${ }^{1}$ Pesquisadora Científica do Instituto de Saúde da Secretaria de Estado da Saúde de São Paulo. E-mail: claudiab@usp.br.

${ }_{2}^{2}$ Pesquisadora Científica do Instituto de Saúde da Secretaria de Estado da Saúde de São Paulo, Mestranda do Programa de Ciências Ambientais da USP.
} 


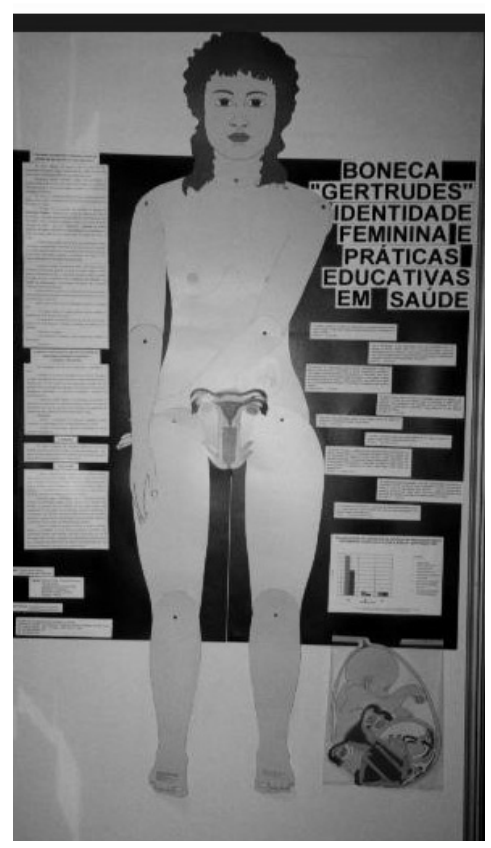

O desenvolvimento da pesquisa "Boneca

Gertrudes: Identidade Feminina e Práticas

Educativas em Saúde" decorre das inúmeras possibilidades de usos que a Boneca vem tendo, enquanto material didático, $e$ de sua extrema versatilidade no enfrentamento de diferentes questões de prevenção e de educação em saúde.

Boneca Gertrudes é um material educativo composto de peças de papelão que, montadas, representam o corpo feminino, em tamanho próximo do natural, em suas várias partes: cabeça, tronco, membros, órgãos genitais e os diversos estágios da gestação.

Utilizada, originalmente, em programas de educação em saúde da mulher, foi sendo, aos poucos, incorporada a outros programas educativos, diversificando, assim, seus usos potenciais. Hoje, Boneca Gertrudes é

utilizada em diferentes programas e atividades educativas. Por ser um material pedagógico versátil, é utilizada na discussão de diversas temáticas da educação em saúde, em programas dirigidos a diferentes faixas etárias: anatomia e fisiologia do corpo feminino; reprodução; gestação, nascimento $e$ parto; amamentação; sexualidade, práticas sexuais, doenças sexualmente transmissíveis e AIDS; papéis sexuais; prevenção de doenças; prevenção no uso de drogas. Este potencial faz com que seja utilizada tanto por Serviços Públicos de Saúde como por Serviços Públicos de Educação e Promoção Social e, também, por Organizações Não Governamentais (ONG's) da área social, preocupadas com a capacitação $e$ formação de lideranças voltadas para um trabalho preventivo.

\section{Contexto de criação}

Em 1984, o Ministério da Saúde criou o PAISM - Programa de Assistência Integral à Saúde da Mulher (BRASIL. Ministério da Saúde, 1984) - que propunha atividades de assistência integral clínico-ginecológica e educativa a mulheres, voltadas para o aprimoramento do controle pré-natal, parto $e$ puerpério; a abordagem de problemas da adolescência até a terceira idade; o controle das doenças de transmissão sexual, do câncer cérvico-uterino e mamário e a assistência para concepção e contracepção.

$\mathrm{O}$ conceito de integralidade da assistência, presente nas diretrizes gerais do programa, acima referidas, pressupunha uma prática que permeasse todos os níveis de atenção (educativa, preventiva e curativa) e, conseqüentemente, uma apropriação, pela clientela, dos conhecimentos necessários a um maior controle sobre sua saúde. A mudança do papel social da mulher - sua inserção no mercado de trabalho, conquista de direitos sociais $e$ transformações desencadeadas pelos movimentos femininos $e$ 
feministas - tornava necessária a introdução de práticas até então quase inexistentes, como o acesso a métodos e técnicas de controle da fertilidade, o acompanhamento das repercussões bio-psico-sociais da gravidez não desejada, abortamento, atendimento às adolescentes e aleitamento materno, entre outros.

Entretanto, a introdução, na rede de serviços de saúde, de um programa que incorporava a questão da identidade feminina e procurava ver a mulher em relação a seu corpo e sexualidade e as representações que ela estabelecia do significado social da maternidade, tornou fundamental repensar a prática dos serviços de saúde realizadas até então (Barbieri, 1991).o programa veio explicitar a necessidade de se estabelecer uma comunicação com a população usuária, no sentido de socializar a prevenção, alterando, profundamente, a prática educativa em saúde de então: de apenas informativa para desencadeadora de mudanças. Uma prática educativa que possibilitasse, à própria mulher, ter maior domínio sobre as relações de corpo e saúde.

Ao colocar em pauta questões como maternidade e contracepção, corpo $e$ sexualidade, verificou-se que as que apresentavam maiores dificuldades de serem discutidas e introduzidas na atenção à saúde da mulher eram as do corpo e da sexualidade porque, somadas aos tabus e preconceitos comuns a todas as mulheres, colocava-se o entrave do discurso, disciplinador $e$ neutralizador do corpo e da sexualidade, biologicamente abstraído de suas outras peculiaridades, dos profissionais de saúde, determinado pela sua formação técnica. Este tipo de discurso era comum na prática dos serviços e dos vários profissionais e estava, também, incorporado pelos serviços de educação em saúde (Barbieri, 1991; Lobo, 1989 ). A introdução das relações sociais de gênero na dinâmica do processo saúde-doença na rede, ou seja, a identidade feminina em sua dimensão corporal da maternidade e da sexualidade, desencadeou a necessidade de novos processos educativos tanto internos à rede, relativos aos recursos humanos, como externos, relativos à interação com a clientela.

Neste contexto, constituiu-se, no Estado de São Paulo, um projeto coletivo que integrava representantes do Programa de Saúde da Mulher da Secretaria de Estado da Saúde, do Conselho da Condição Feminina, do Núcleo Materno-Infantil do Instituto de Saúde, além do então denominado Serviço de Educação do Instituto de Saúde, que foi incorporado ao processo, tendo em vista o trabalho que vinha desenvolvendo de releitura crítica dos materiais educativos em saúde. A principal demanda deste coletivo ao Serviço de Educação do Instituto de Saúde, no tocante ao aspecto educativo do programa, era a necessidade de produzir um material que:

- não falasse apenas dos órgãos genitais femininos mas sim da mulher como um todo;

- se aproximasse o mais possível do corpo físico da mulher (forma, tamanho etc.) a fim de permitir o "encaixe" dos métodos contraceptivos dispositivo intra-uterino (DIU) e diafragma;

- pudesse ser manuseado;

- fosse construtivo, no sentido de compor partes e todo, montagem e desmontagem;

- fosse lúdico. 
Referenciada por estes critérios foi desenvolvida a Boneca Gertrudes, dentre um conjunto de materiais de apoio. A Boneca, além de permitir uma visão integral do corpo feminino, permite também uma ação participativa por meio de técnicas de impressão e expressão corporal.

Esta característica peculiar da Boneca Gertrudes acabou por diferenciá-la do restante do material educativo até então disponível na área de educação em saúde. Ela acabou por revelar um potencial inovador, decorrente do fato de expressar a complementariedade entre corpo e identidade feminina, além de propiciar práticas pedagógicas dialógicas, num escopo construtivista.

\section{Metodologia}

Foi realizado um estudo da mobilidade atual do instrumento pedagógico Boneca Gertrudes, concebido como um retrato dos diversos contextos educativos em saúde nos quais ela é utilizada.

Tendo em vista que os objetivos da pesquisa diziam respeito essencialmente ao caráter qualitativo do instrumento pedagógico, foi utilizada a entrevista individual como fonte primária de dados.

A utilização de documentos técnicos - relatórios e atas de reuniões do Ministério da Saúde, da Secretaria de Estado da Saúde/SP e do Instituto de Saúde/SES/SP, referentes ao PAISM e ao Manual de Gestantes e, também, o próprio Manual de Gestantes e os materiais educativos a ele vinculados possibilitou a reconstrução do contexto de surgimento da Boneca Gertrudes e forneceu os elementos para o delineamento das entrevistas realizadas.

Procedeu-se, também, ao mapeamento das atividades educativas, atualmente desenvolvidas, que utilizam a Boneca Gertrudes junto à rede de Centros de Saúde (Secretaria de Estado da Saúde de São Paulo), Unidades Básicas de Saúde (Secretaria Municipal de Saúde de São Paulo) e aos diferentes serviços sociais, de educação e informação em saúde (institucionais ou não), além da sistematização de bibliografia $e$ documentação suplementar relativa ao tema.

Foram contatados serviços de saúde estaduais e municipais de São Paulo, Grande São Paulo e interior do Estado de São Paulo, procurando-se, dentro das possibilidades, criar um universo mais abrangente e representativo do Estado. Este rastreamento constituiu a fase preliminar da definição do universo de informantes-chave.

$\mathrm{Na}$ impossibilidade de se entrevistar todo o universo daqueles que se utilizam, atualmente, do instrumento pedagógico estudado, optou-se por entrevistar informantes-chave dos três segmentos básicos (Brioschi \& Trigo, 1987; Ludke \& André, 1986; Minayo, 1993): a) profissionais da rede básica de serviços de saúde, que se constituíram em informantes naturais, já que a Gertrudes foi idealizada e concretizada em seu bojo, tornando-se o "locus" de principal utilização do material; b) profissionais que atuam em atividades de educação e informação, não especificamente da área da saúde (educação formal, promoção social e outros). Tendo em vista o caráter educativo do material (Boneca Gertrudes), considerou-se importante avaliar sua repercussão nestes serviços que não executam procedimentos médicoclínicos etc) integrantes de movimentos sociais organizados em ONG's de 
mulheres e adolescentes, inseridos na discussão sobre assistência médica integral, questão feminina, sexualidade e outros, temas estes que estiveram presentes no surgimento e na posterior utilização da Boneca Gertrudes. Cabe ressaltar que a seleção para a amostra dos Serviços de Saúde, Bem Estar e das ONG's foi feita uma vez que estas instituições expressam, de modo exemplar, o processo educativo informal.

A pesquisa foi realizada junto a vinte instituições de três tipos: Serviços Públicos de Saúde - Municipais e Estaduais -, outros Serviços Públicos não ligados diretamente à área de saúde - Educação e Bem Estar Social -, denominados de Diversos, e ONG's do Estado de São Paulo, agrupadas nas seguintes regiões: Capital, Grande São Paulo e Interior (Tabela 1).

TABELA 1 - Distribuição do tipo de instituição, segundo região, julho a dezembro de 1995 e janeiro de 1996.

\begin{tabular}{|l|c|c|c|c|}
\hline Localidade & $\begin{array}{c}\text { Serviços } \\
\text { de Saúde }\end{array}$ & $\begin{array}{c}\text { Serviços Públicos } \\
\text { Diversos }\end{array}$ & $\begin{array}{c}\text { Organizações Não } \\
\text { Governamentais }\end{array}$ & TOTAL \\
\hline Capital & 04 & 02 & 01 & 07 \\
Grande São Paulo & 06 & - & - & 01 \\
Interior & 06 & - & 02 & 07 \\
\hline TOTAL & 16 & 02 & 20 \\
\hline
\end{tabular}

FONTE: Pesquisa "Boneca Gertrudes: identidade feminina e práticas educativas em saúde", Núcleo de Investigação em Educação em Saúde do Instituto de Saúde da Secretaria de Estado da Saúde de São Paulo (NIES/IS/SES-SP), 1996.

\section{Resultados}

Como conseqüência da constatação de que Boneca Gertrudes vem tendo grande diversidade de usos, procurou-se verificar as causas de sua ampla utilização, nos diferentes e diversos Programas Educativos em Saúde: de Adolescentes, Prevenção de doenças sexualmente transmissíveis e AIDS, Saúde Reprodutiva em geral e outros.

Um dos fatores apontados pelos entrevistados como facilitador do trabalho educativo com a Boneca Gertrudes é a possibilidade de seu uso coletivo. Nos Serviços Públicos de Saúde Estaduais ou Municipais - Boneca Gertrudes é utilizada sempre em atividades grupais, em conjunto com outras técnicas e dinâmicas como dramatização do parto e relaxamento, além de colagens, cartazes, álbuns e apresentação dos métodos contraceptivos (DIU, diafragma,

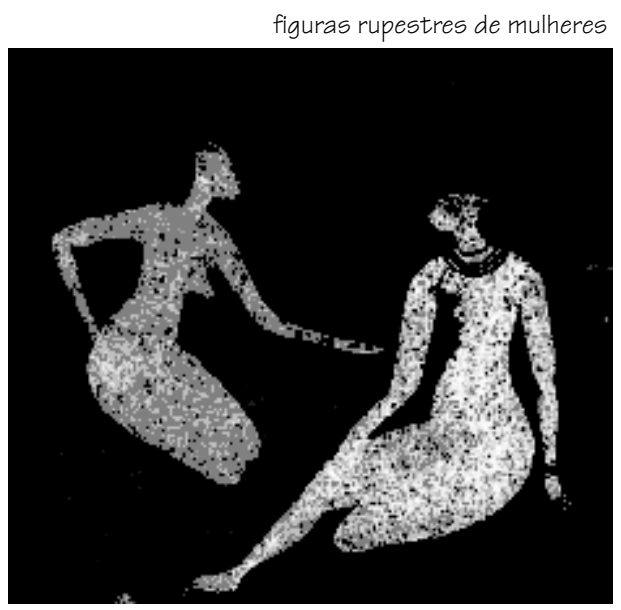


preservativo, pílula); a lousa também é utilizada. Também não estão descartados outros recursos audio-visuais como vídeos e slides, por exemplo.

Nas atividades com adolescentes é predominante o uso da montagem dos corpos feminino e masculino (uma recriação dos profissionais dos serviços a partir da própria Gertrudes) junto com outras técnicas de dinâmica de grupo que precedem a atividade com Boneca Gertrudes. Em geral, o trabalho é um misto de discussão de sexualidade, corpo e informação biológica:

\footnotetext{
"(...) com os adolescentes há uma fase preliminar onde um menino e uma menina deitam-se no chão e seus corpos são contornados com giz. O grupo é dividido e cada um deve desenhar o aparelho reprodutor masculino e feminino nos respectivos contornos. Depois montam nos Bonecos - a Gertrudes e o Roberto - os aparelhos reprodutores correspondentes. Após a montagem, a equipe vê se a mesma está correta e faz-se uma explanação".
}

Quando a atividade é expositiva, Boneca é fixada em isopor ou apoiada num cavalete e é feita uma explanação dos aspectos anatômicos e fisiológicos do corpo $e$ as peças são colocadas conforme o andamento das explicações. Em algumas situações, à atividade expositiva acrescenta-se a participação dos membros do grupo: pergunta-se aos participantes se sabem onde estão localizados os órgãos do aparelho reprodutor e como é o processo da concepção e solicita-se que coloquem as peças no lugar, no corpo da Boneca:

“(...) as peças internas são distribuídas entre as mulheres e cada uma vai colocando a parte que lhe coube onde acha que é o lugar correto, completando o que as outras já fizeram".

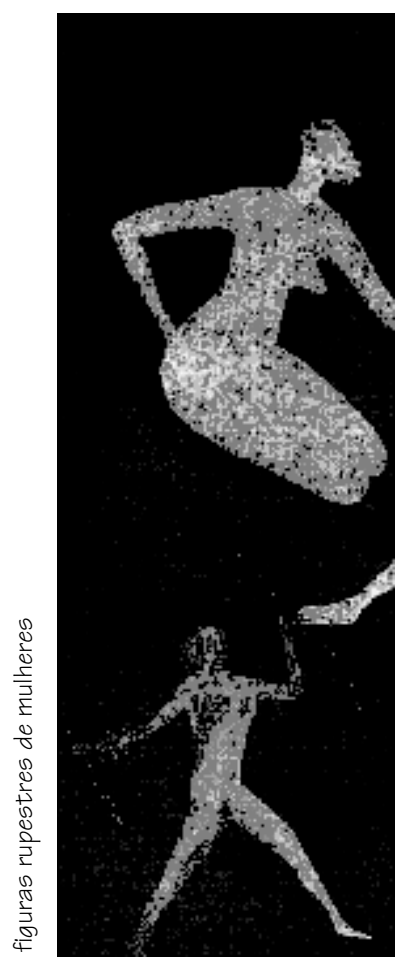

No caso dos Serviços Públicos de Promoção Social e da Educação, o trabalho é realizado em grupos, a não ser que haja necessidade de orientação mais detalhada ou esclarecimentos. Este tipo de trabalho caracterizase tanto por uma orientação para as pessoas como por um processo de dinâmicas de grupo em que se discute sexualidade, papéis sociais da mulher e, também, anatomia e fisiologia. Quanto às ONG's, também existe uma predominância no trabalho desenvolvido em grupo, por meio de oficinas e outras técnicas de trabalho.

Outro fator importante, quanto aos múltiplos usos efetivos da Boneca Gertrudes, revelou-se na avaliação dos informantes que lhe atribuíram a possibilidade da concretitude do aprendizado, porque é de tamanho natural e permite a construção da imagem da mulher. Quando as mulheres manuseiam as partes fragmentadas, buscando a construção da Boneca, elas entram em contato com a construção delas próprias, de seu próprio corpo. Ao possibilitar que as peças dos 
órgãos internos sejam visualizadas e colocadas no próprio corpo, Boneca Gertrudes favorece a percepção do todo:

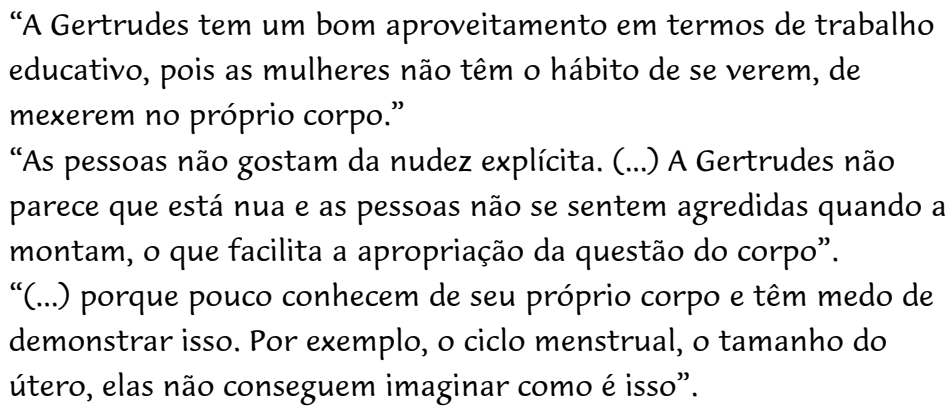

O fato de poder trabalhar com as partes e o todo em tamanho natural, permite a apreensão de que o corpo e os órgãos fazem parte de um todo integrado, com ligações entre si e com o resto do corpo. Isto também possibilita a desmistificação de tabus e preconceitos frente ao corpo:

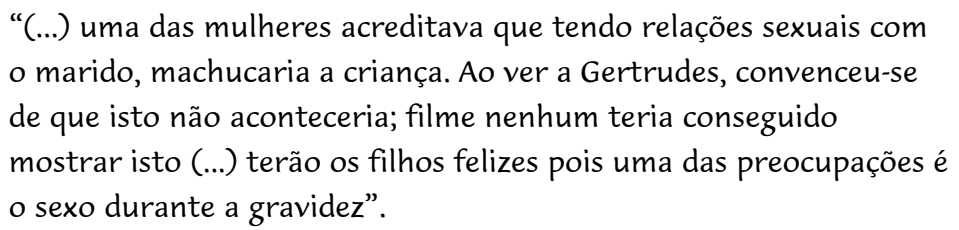

Outro aspecto bastante valorizado é o fato de ser um recurso de mais fácil utilização do que o vídeo, além de não ser um instrumento que estimule a passividade, pois "não é platônico":

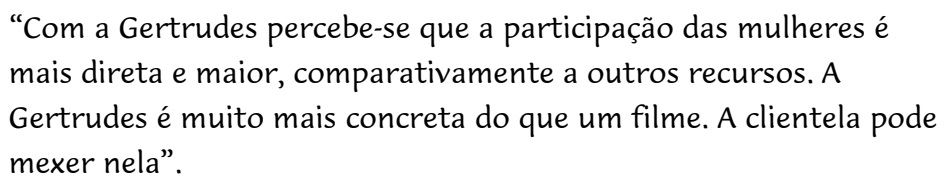

Sua forma também estimula o conhecimento, sem necessitar da habilidade de leitura e escrita, o que a torna adequada para o uso com uma população eventualmente iletrada ou semi-alfabetizada, geralmente excluída de outras atividades em que o saber ler e escrever é requisito básico. Como o trabalho com Gertrudes se dá em nível visual e tátil não requer, necessariamente, que a população-alvo seja alfabetizada: "(...) as pessoas querem tocá-la, ver com as mãos”.

Mesmo tendo por objetivo principal a aprendizagem de aspectos anatômicos e fisiológicos do corpo humano, a utilização do material também permite a abordagem de outras questões como valores e sentimentos relacionados com a sexualidade humana. É muito fácil a "interação" entre os participantes e os bonecos e, muitas vezes, os participantes atribuem a eles características humanas, fazendo com que dialoguem entre si, conversando sobre suas dúvidas com relação às questões de sexualidade, como: órgãos sexuais masculinos e femininos, relação sexual, virgindade, desejo sexual, 
"tesão", homossexualidade, "travesti" e outros: "Quando se está falando do aparelho reprodutor, é muito importante que o cérebro apareça, porque você deseja, e pode intervir na questão de ter ou não ter filhos".

Os bonecos também oferecem a possibilidade de uma "dramatização" representando a aproximação entre um homem e uma mulher e uma relação sexual. Estes aspectos são mais presentes nos trabalhos desenvolvidos com adolescentes.

A possibilidade de abordar questões relativas ao corpo, de um modo mais concreto e participativo, "traz um encanto para o grupo, traz a vontade de brincar, de conversar”. Para os participantes, então, não se coloca a questão de acertar ou errar; eles trabalham, através da Boneca Gertrudes, a "desinformação com descontração".

Para os educadores, os usuários reagem e interagem com a Boneca de forma bastante positiva. As pessoas se identificam com ela, e isso é percebido pela satisfação que demonstram em manuseá-la, solicitando-a com freqüência no decorrer das atividades.

Em relação ao material em si, os educadores manifestaram-se positivamente quanto à possibilidade que Boneca Gertrudes oferece de estimular a participação dos membros do grupo, pela sua mobilidade - o que facilita o manuseio - e por criar um clima lúdico, descontraído. Para os entrevistados, estes são fatores que contribuem para a retenção do conhecimento por parte dos educandos, uma vez que o aprendizado se dá no plano do real, do concreto.

\section{Conclusões}

O potencial coringa deste material didático chamado Boneca Gertrudes foi o responsável pela sua adaptabilidade a públicos diferenciados em sexo e faixa etária e a diferenciados riscos e agravos à saúde (saúde da mulher, prevenção de drogas e doenças sexualmente transmissíveis e AIDS). Ela resulta em uma solução simples para o enfrentamento de questões complexas como a idéia da integralidade da atenção. Por isso, Boneca conseguiu contemplar a amplitude e multiplicidade de questões em saúde da mulher que haviam sido postas originalmente pelo PAISM.

Ao permitir a concretização do corpo feminino, Gertrudes facilita a abstração capacitando para o aprendizado. Ao educando é permitido um espaço e uma atitude própria para estruturar os conceitos adquiridos a seu modo. Boneca possibilita, ainda, a participação ativa dos educandos numa relação de troca de experiência e conhecimentos entre educadores $e$ educandos e entre educandos entre si, pelas técnicas de expressão e impressão. O fato de ser manipulável, de as pessoas "poderem colocar as mãos” nas peças, suscita a discussão entre as partes, facilitando a interação de todos os envolvidos no processo educativo. Ela estimula a ação e não a passividade.

Também no sentido de concretizar a representação que as mulheres, os adolescentes e outros grupos têm da sexualidade e do corpo, Boneca é um instrumento bastante adequado pelo fato de reproduzir o tamanho adulto, ser um jogo de montagem de peças e permitir a reprodução do 
funcionamento biológico interno da mulher. Isto constitui um fator que facilita a visualização, a abstração $e$ a memorização - elementos

fundamentais para a representação concreta do aprendizado. O manuseio (pegar, ver e colocar partes) propicia que as mulheres se vejam na Boneca, comparem e diferenciem os órgãos internos (que não se vêem), o que permite que as pessoas "olhem com as mãos, pois falar é uma coisa e fazer é outra".

Outro aspecto que merece ser destacado $e$, também está relacionado com seu formato, que reproduz em tamanho natural o corpo feminino com o detalhamento dos órgãos internos, é a possibilidade que isto oferece de permitir a visualização do corpo feminino adulto $e$ a percepção dele de modo concreto. Nisto é contemplado o outro aspecto relevante do potencial educativo da Boneca Gertrudes, que é a possibilidade de identificação do material com o usuário, tão importante para que qualquer material pedagógico seja incorporado pelo grupo que se pretende atingir, enquanto população-alvo de uma atividade educativa.

Boneca Gertrudes facilita, entre as mulheres, a

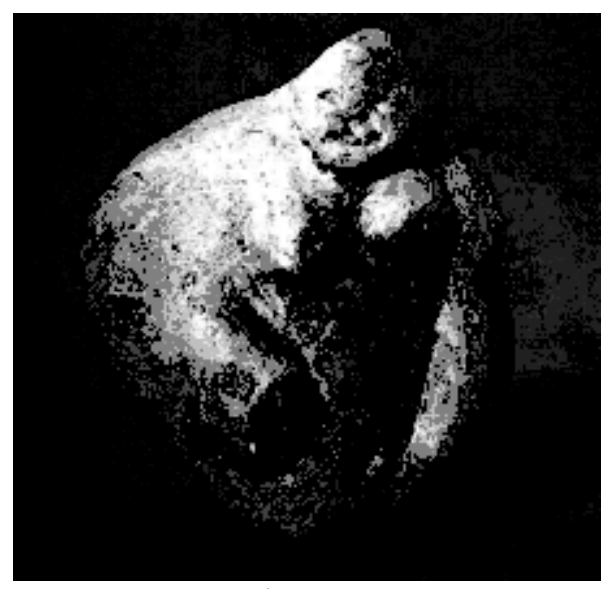

Figura feminina do Neolítico encontrada em jazida de mineração em Norfolk, Inglaterra. compreensão de si mesmas (física $e$ organicamente) e, conseqüentemente, a interação educativa entre elas - que, mesmo sendo adultas, não conhecem o próprio corpo e seu funcionamento.

Outro elemento, intrínseco à própria Boneca, é seu potencial dialógico enquanto material didático, que pressupõe como passos da aprendizagem: $\left.1^{\circ}\right)$ a codificação da situação, no sentido de sua percepção global; $2^{\circ}$ ) a decodificação da situação, enquanto decomposição em partes para exame, estudo e análise; $3^{\circ}$ ) problematização da situação, contextualização da vivência a partir da análise crítica. Neste sentido, o principal foco de uma ação pedagógica dialógica não é a criação de igualdade entre educadores $e$ educandos, mas sim a construção de um espaço democrático em que as diferenças não sejam antagônicas. O diálogo deve ser a confirmação conjunta de educadores e educandos no ato de conhecer. Este processo torna explícita a necessidade de uma re-organização/reconstrução da atuação dos recursos humanos. Boneca Gertrudes exige, do profissional envolvido, sua desconstrução/desmontagem, para uma reconstrução/ montagem coletiva, em conjunto com o usuário.

A utilização da Boneca Gertrudes, ao estar presente em atividades educativas não inseridas nos processos de educação formais (escolares) $e$ desenvolvidas em instituições de serviços públicos, entre técnicos e usuários com faixas etárias, geralmente, da adolescência para cima - reforça o aspecto já destacado de propiciar a troca de experiências e conhecimentos entre os participantes e, assim, o diálogo. É contemplada, também, a aprendizagem pela via da psicomotricidade, como um estágio facilitador, principalmente quando se trata das populações-alvo atingidas pelos trabalhos desenvolvidos pelas instituições e/ou entidades escolhidas para compor esta investigação, 
geralmente grupos excluídos dos processos mais formais de instrução.

Todos esses pressupostos estão presentes nas situações em que Gertrudes foi utilizada. A presença do diálogo foi uma condição. Tratava-se de falar e refletir sobre o vivenciado. Do conjunto dos entrevistados, a grande maioria considerou como um dos aspectos mais significativos deste material a possibilidade de concretitude do aprendizado, em função de seu tamanho, próximo ao real, e na agilidade construtiva, pela mobilidade das partes.

A pertinência da elaboração de instrumentos pedagógicos, na área de educação em saúde, é uma justificativa para a pesquisa que foi realizada, na medida em que a utilização de instrumentos pedagógicos como recursos facilitadores ou objetos intermediários da/na prática educativa é bastante difundida na área de educação como um todo e também na área de educação em saúde, e tem sido apontada como uma estratégia que pode trazer bons resultados (Chiesa \& Westphhal, 1995; Vargas \& Romeiro, 1992). Os instrumentos pedagógicos podem ser representados e figurativos, o que possibilita a concretitude de conteúdos abstratos. A experiência pedagógica de se deparar com um objeto intermediário que configura a idéia, a representação, permite um aprendizado mais completo, pela similaridade e identidade.

\section{Referências bibliográficas}

BARBIERI, T. Sobre la categoría género: una introducción teóricometodológica. In: AZERÊDO, S., STOLCKE, V. (Coords.) Direitos reprodutivos. São Paulo: Fundação Carlos Chagas, 1991. p.25-45.

BRASIL. MINISTÉRIO DA SAÚDE. Assistência integral à saúde da mulher: bases de ação programática. Brasília, Centro de Documentação do Ministério da Saúde, 1984.

BRIOSCHI, L., TRIGO, M.H.B. Relatos de vida em ciências sociais: considerações metodológicas. Ciênc. Cult., v.39, p.631-37, 1987.

CHIESA, A.M., WESTPHAL, M.F. A sistematização de oficinas educativas problematizadoras no contexto dos serviços públicos de saúde. Saúde em Debate, v.46, p.19-22, 1995.

LOBO, E.S. Os usos do gênero. In: Relações sociais de gênero $X$ relações de sexo. Departamento de Sociologia - Área de PósGraduação/Núcleo de Estudos da Mulher e Relações Sociais de Gênero, 1989. p.76-87.

LUDKE, M., ANDRÉ, M.E.D.A. Pesquisa em educação: abordagens qualitativas. São Paulo: EPU, 1986. .

MINAYO, M.C.S. O desafio do conhecimento: pesquisa qualitativa em saúde. São Paulo: HUCITEC/ABRASCO, 1993.

VARGAS, E.P., ROMEIRO, E.A. (Coord.). Práticas de educação em saúde: programa de assistência integral à saúde da mulher..Rio de Janeiro, Centro de Saúde-Escola Germano Sinval Faria, Escola Nacional de Saúde Pública, 1992.

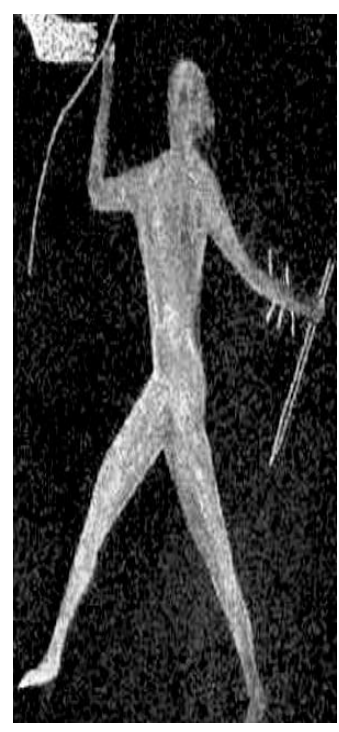


Diversidade de usos da Boneca Gertrudes, segundo o tipo de instituição, julho a dezembro de 1995 e janeiro de 1996.

\begin{tabular}{|c|c|c|}
\hline PROGRAMA EDUCATIVO & POPULAÇÃO-ALVO & TEMÁTICAS ABORDADAS \\
\hline $\begin{array}{c}\text { Programa de Saúde da } \\
\text { Mulher }\end{array}$ & $\begin{array}{l}\text { Mulheres e casais de } \\
\text { qualquer faixa etária }\end{array}$ & $\begin{array}{l}\text {-anatomia e fisiologia do corpo feminino; } \\
\text {-anti e contracepção; } \\
\text {-desenvolvimento da gestação; } \\
\text { preparação para o parto e } \\
\text { amamentação; } \\
\text {-informações sobre recém nascidos; } \\
\text {-informações legais sobre a maternidade; } \\
\text {-câncer ginecológico. }\end{array}$ \\
\hline $\begin{array}{c}\text { Programa de Adolescen- } \\
\text { tes }\end{array}$ & $\begin{array}{l}\text { Ambos os sexos } \\
\text { de } 12 \text { a } 17 \text { anos }\end{array}$ & $\begin{array}{l}\text {-reconhecimento do corpo humano; } \\
\text {-conhecimento dos aparelhos } \\
\text { reprodutores feminino/masculino; } \\
\text {-mudanças de comportamento; } \\
\text {-sexualidade; } \\
\text {-métodos contraceptivos; } \\
\text {-DST/AIDS; } \\
\text {-drogas. }\end{array}$ \\
\hline Prevenção de DST/AIDS & $\begin{array}{c}\text { Comunidades } \\
\text { organizadas (Escolas, } \\
\text { Sociedade Amigos de } \\
\text { Bairro, etc) }\end{array}$ & $\begin{array}{l}\text {-práticas sexuais; } \\
\text {-prevenção de doenças. }\end{array}$ \\
\hline $\begin{array}{c}\text { Formação e Capacitação } \\
\text { em Recursos Humanos }\end{array}$ & $\begin{array}{c}\text { Professores, Assistentes } \\
\text { Sociais, Pagens e } \\
\text { Auxiliares }\end{array}$ & $\begin{array}{l}\text {-anatomia e fisiologia dos corpos } \\
\text { masculino e feminino; } \\
\text {-sexualidade; } \\
\text {-prevenção das DST/AIDS e drogas. }\end{array}$ \\
\hline $\begin{array}{c}\text { Formação e capacitação } \\
\text { de lideranças }\end{array}$ & $\begin{array}{c}\text { Adolescentes, Direção } \\
\text { de Entidades ou } \\
\text { Movimentos, Pais, } \\
\text { Profissionais } \\
\text { interessados }\end{array}$ & $\begin{array}{l}\text {-papéis sexuais e sociais; } \\
\text {-sexualidade; } \\
\text {-prevenção das DST/AIDS; } \\
\text {-drogas. }\end{array}$ \\
\hline
\end{tabular}

FONTE: Pesquisa "Boneca Gertrudes: identidade feminina e práticas educativas em saúde”, NIES/IS/SES-SP, 1996. 
BÓGUS, C. M., IANNI, A. M. Z. Muñeca Gertrudis: identidad femenina y prácticas educativas en salud. Interface _ Comunicação, Saúde, Educação, v.3 n.4, 1999.

La implementación, en 1984, del Programa de Asistencia Integral a la Salud de la Mujer, al incorporar la cuestión de la identidad femenina - buscando ver a la mujer en ralación a su cuerpo y sexualidad y el modo en que estas representaciones se relacionaban al significado social de la maternidad --volvió fundamental repensar la práctica de los servicios de salud realizada hasta entonces. Con el objetivo de apoyar la acción educativa de los profesionales de salud se elaboró, en la época, un instrumento pedagógico: la Muñeca Gertrudis. Esta investigación, realizada en los años 1995 y 1996, verificó el alcance de este instrumento, considerando la diversidad de su uso en las prácticas educativas en salud $y$, principalmente, si este alcance de usos se debía al recurso que constituía pedagógicamente la Muñeca Gertrudis: expresión de la metodología dialógica y concreción del cuerpo femenino. Se pretende contribuir en la discusión de la elaboración de nuevos recursos facilitadores del trabajo educacional que aborden cuestiones de género.

PALABRAS-CLAVE: educación en salud; género y sexualidad; salud de la mujer.

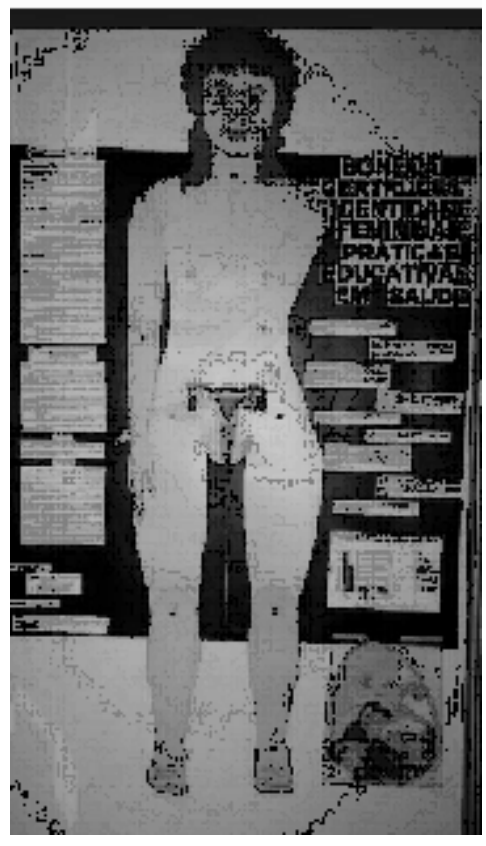

104 Interface - Comunic, Saúde, Educ 4 